\title{
Comparative Analysis of Inquiry Activities in Sino-US High School Biology Textbooks
}

\author{
Yingchun Zhang ${ }^{1,}$, Fen Lin ${ }^{1}$, Xueqin Gaohua ${ }^{1,2}$ \\ ${ }^{1}$ College of Life Sciences, Shaanxi Normal University, Xi'an, China \\ ${ }^{2}$ Xi' an No.8 High School, Xi'an, China
}

Email address:

yingchunzcn@snnu.edu.cn (Yingchun Zhang),635431819@qq.com (Fen Lin),1031163986@qq.com (Xueqin Gaohua)

${ }^{*}$ Corresponding author

\section{To cite this article:}

Yingchun Zhang, Fen Lin, Xueqin Gaohua. Comparative Analysis of Inquiry Activities in Sino-US High School Biology Textbooks. Science Journal of Education. Vol. 5, No. 5, 2017, pp. 200-205. doi: 10.11648/j.sjedu.20170505.13

Received: July 5, 2017; Accepted: July 17, 2017; Published: August 11, 2017

\begin{abstract}
The arrangement of inquiry activities in the textbooks, to a certain degree, affects the quality of inquiry learning activities. The research made a comparative analysis of the inquiry activities in Chinese high school biology compulsory textbooks (PEP edition) and American high school biology textbooks (Biology: the Dynamics of Life) from the inquiry types, equipments, arrangements of teacher-students interactions and etc. The research suggests that in order to improve the quality of inquiry learning activities, China could enrich the content of textbooks, develop the equipments of activities and optimize the detail of teaching activities.
\end{abstract}

Keywords: Textbook Comparison, Inquiry Activities, High School Biology

\section{Introduction}

Since 1980s, in order to enhance the national core competitiveness and cultivate creative talents, countries in the world have carried out the reform of basic education. The reform of science teaching which focuses on scientific inquiry has been recognized by countries whose education is developed. [1] The General High School Biology Curriculum Standard (Experimental edition) (Curriculum Standard hereafter) of China advocates inquiry learning to promote the change of students' learning style. [2] Although education reform is going deeper, inquiry teaching still faces many challenges when practices in school. For example, there is a considerable distance between the teaching and learning behavior in inquiry activities and the essential requirements of inquiry teaching, and there are many difficulties in the design and implementation of inquiry activities. These problems not only affect the quality of inquiry activities, are also bad to cultivate creative talents. The United States is one of the countries whose education are developed, and its' scientific inquiry teaching has already occupied a large proportion in the classroom teaching. From the aspect of comparison between two countries' textbooks, the research studies the types of inquiry activities, the experimental equipments, the arrangements of teacher-students interaction and etc. The research aims to promote the quality of biological inquiry learning activities in China.

In recent years, the comparative research on Sino-US high school biology textbooks mainly focused on the overall structure and content of textbooks [3, 4], a certain unit or section [5-8] and the history of science [9], critical thinking [10], exercises [11-13], instructional resources [14] and experiments [15] in the textbooks, discussing similarities and differences between Sino-US mainstream textbooks. The mainstream biology textbooks in American high schools are Biology: the Dynamics of Life and BSCS textbooks Biological Science, while the most representative one in Chinese are Chinese high school biology compulsory textbooks (PEP edition). However, there are only a few of comparative studies about inquiry activities in Sino-US biology textbooks. For example, Wenshuo Zhang [16] conducted a comparative study on inquiry activities in American BSCS textbooks Biological Science and Chinese high school biology compulsory textbooks (PEP edition). The 
main dimensions of comparison were the types of activity, the basic elements of activity, and the ability that students would develop during the activity. There has been no comparative study on inquiry activity in the American textbook Biology: the Dynamics of Life.

\section{Comparison on the Types of Inquiry Activities}

Scientific inquiry activities must originate from a concrete problem [17] Problem not only is a driving force to promote students' learning process and cognitive process, but also is an important work in the process of knowledge acquisition. Based on this characteristic, all activities in Chinese high school biology compulsory textbooks (PEP edition) and American high school biology textbooks (Biology: the
Dynamics of Life) are classified, and 31 inquiry activities from Chinese textbooks and 41 inquiry activities from American textbooks are selected respectively for comparative analysis.

According to the content of the inquiry activities, the arrangements of inquiry activities in two countries' textbooks can be divided into three types: investigative inquiry, experimental inquiry and communicative inquiry [18]. The number of each activity type in two countries' textbooks is not same (see Figure 1). Experimental inquiry activities account for $38.7 \%$ in China, but account for $61 \%$ in America; Communicative inquiry activities account for $38.7 \%$ in China, but account for $22 \%$ in America; Investigative inquiry activities in China account for about $22.6 \%$, but account for $17.1 \%$ in America.

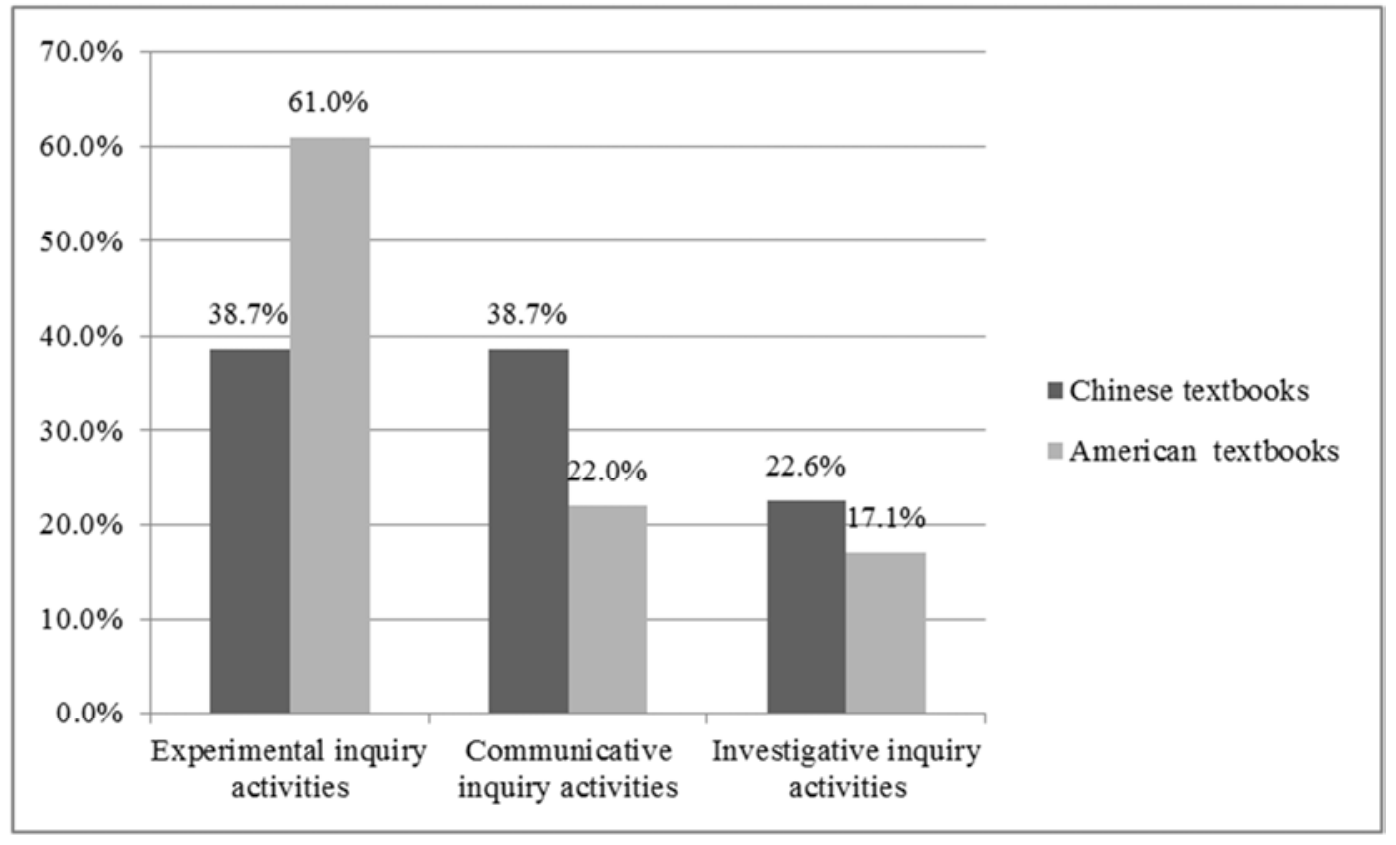

Figure 1. The statistical classification of inquiry activity modes in Sino-US biology textbooks.

From the contrast of the proportion of each activity type, it can been seen that the proportion of experimental inquiry activities in American textbooks is far more than that in China, which indicates that American high school biology teaching attaches great importance to experiment, because the experiment is an important platform to train students' practical ability and critical thinking ability, and it is also the key point of cultivating creative talents. In particular, experiments in American textbooks not only verify and reproduce key and difficult knowledge, but also expand and apply the knowledge in textbooks, such as "to test whether drugs contain alcohol", "what is the best egg shape" and "to determine the number of stomata on a leaf". These arrangements play a certain role in guiding the development of high school students' abstract thinking ability, and can systematically help students sort out all the solutions to a certain problem as well. Experiments in American textbooks arrange and combine these solutions rationally, and let students experience the basic process_raise a question, establish hypotheses, design experiments, conduct an experiment, draw a conclusion, which conforms with the cognitive, physical and mental development characteristic of the students in this stage. Although investigative inquiry activities in American textbooks account for only $17.1 \%$ of the total, it does not mean that they lay less emphasis on investigative inquiry activities. The fact is that the proportion of investigative inquiry activities in elementary and middle school compared to high school is much higher in the United States. It indicates that American textbooks in high school pay more attention to train students' experimental ability. Since the development of biology is based on the experiments, biological experiments have an important effect on students' learning of critical thinking, scientific methods and scientific spirit.

The proportion of the experimental inquiry activities and communicative inquiry activities in the Chinese textbooks are 
the same, but the proportion of the investigative inquiry activities is higher than the United States. The result shows that investigative inquiry activities still are key points in Chinese high school, and the experimental inquiry activities compared with American textbooks have not been occupied a prominent position in Chinese high school. This arrangement is consistent with the present situation of Chinese education. Because in practice, experimental inquiry activities in a considerable part of school cannot be implemented well still, as some schools in the education-underdeveloped areas are often hampered by traditional teaching habits, replacing students' inquiry experiments with teachers' demonstrating experiments and blackboard experiments (the teachers write the experimental steps on the blackboard and the students recite them, intending to prepare for the test). There is a certain gap between inquiry learning activities arranged by textbooks and the practice in school. When practice in school, some educators have not realized that obtaining knowledge only by indirect methods is bad for the formation of students' creative practice ability. From the aspects of cultivating innovative talents, it's not difficult to see that for the arrangement of Chinese experimental inquiry learning activities, textbooks are still in leading stage, and the teaching research and implementation of experimental inquiry activities have not become autopsyche consciousness of schools especially in rural schools. Compared with American science education, Chinese science education still has a long way to go in this aspect.

\section{Comparison on Experimental Equipments of Inquiry Activities}

Experimental equipmentsare the basic guarantee for the quality of biological inquiry learning activities. Experimental equipment used in the inquiry activities can be divided into three categories, one is the laboratory supplies, including the commonly used equipment, experimental equipment or drugs; Another one is biological experimental materials, including animals, plants and microorganisms; The last one is daily necessities, such as desk lamps, cellophane, coffee cup, table tennis and etc. By analyzing the equipments used in inquiry activities in two countries' textbooks, it shows that:

\subsection{The Types of Equipment Are Relatively Rich in American Inquiry Activities}

According to students' cognitive law, teaching often needs to start from perceptual knowledge, and then rise to rational knowledge. Perceptual knowledge is the foundation and the experiment is an important part of perceptual knowledge, therefore, experimental equipment is a basic requirement for carrying out an experiment successfully.

In the layout design of the activities equipments, inquiry activities in American textbooks select some common daily necessities, in addition to the common laboratory instruments, chemicals and biological experimental materials (see table 1).
The daily necessities are very extensive, including desk lamps, mark pens, cable, table tennis balls, golfballs, coffee, tea, alcohol, toothpicks, cola and other items. For instance, equipments used in inquiry activities "to explore the factors affecting photosynthesis", not only include professional experimental instruments, but also include "ropes", "colored cellophane", "watches", "network" and other daily necessities. Rich activity equipments can stimulate students' interest in exploring and provide a platform to develop students' imagination as well, which is conducive to training students' imagination and creativity. The use of daily necessities can guide students to observe life and experience life, lead students to think about the phenomena of life, learn the knowledge migration and link theoretical knowledge with practical application.

Compared with the American textbooks, the design of experimental equipments in inquiry activities in Chinese textbooks is more perfect, but nearly no daily necessities show up. The arrangement of textbooks ensures the standardability of experimental operation, but from the level of implementation, obviously, the experimental cost is relatively high, so that some schools may give up the experiment because of the high cost, which results in inquiry activities that should be done fail to carry out normally. Meanwhile, the simplification of equipments will narrow some teachers' teaching vision and make teachers think that inquiry activities can only use laboratory supplies and biological experimental materials, and then they ignore the experimental function of daily necessities. From the perspective of science education, the design that textbooks do for the standardability of inquiry activities equipments is obviously beyond doubt, but how to deal with the relationship between standardability and the use of local materials is worth in-depth studies in the teaching practice. Curriculum Standard in China stresses the teaching ideas of "focusing on the linkages with the real-life". Except that textbooks need to strengthen the leading function for this aspect, the more important is that under the premise of ensuring scientificity and standardability, schools should through the teaching research explore daily necessities that can be applied to inquiry learning activities as more as possible from schools' social environment and living environment. Because the process of exploring experiment materials is an excellent training process for the formation of students' imaginative thinking ability, practical ability, innovative consciousness and creative spirit. Chinese textbooks (PEP edition) have made a useful attempt in this field. For example, the textbooks have specially opened the "Model Construction" column to guide teachers and students in using daily necessities to construct biological models. So the textbooks use polyfoam, templates, plastic bags, cloth and other materials in life in the activity "trying to make a three-dimensional structure model of eukaryotic cells". It indicates that the textbooks have paid attention to the guiding function of teaching ideas "closely linking the theory with practice" to inquiry teaching activities. 
Table 1. The statisticstable of inquiry activity equipments in Sino-US biology textbooks.

\begin{tabular}{llll}
\hline Textbooks & laboratory supplies & biological experimental materials & daily necessities \\
\hline Chinese textbooks & $\begin{array}{l}\text { mortar, balance, tweezers, absorbent } \\
\text { paper, iodine, microscope etc. } \\
\text { cylinder, balance, sucrose solution, } \\
\text { American textbooks }\end{array}$ & small soil animals, soil microorganisms & nothing \\
\hline
\end{tabular}

\subsection{The Name of Materials Is Relatively Specific in American Inquiry Activities}

The name of materials in the inquiry activities of Chinese textbooks is not explicit and concrete enough. For example, there are "small soil animals", "soil microorganisms" such expressions in the textbooks, but soil microorganisms and soil animals both are generic names for a class of organisms, including a variety of organisms, however specifically what kind of creature it is. Such expressions of the textbooks often require teachers combining the actual situation of the small soil animals or microorganisms located in local and seasonal soil to distinguish and select, and giving concrete instruction to the students' study. If teachers ignore the relatively general expression of the textbooks or the teachers' professional ability can't keep up, so that they don't process the textbooks' contents to a certain degree, it will lead to a phenomenon that the guidance given to students is not clear. And then students do not know choosing what kind of soil animals and soil microorganisms when they explore, and some students even have the attitude that choose whatever have been seen in the soil to explore, which affects the results of inquiry and also is harmful to the improvement of students' ability. In contrast, the name of equipments is very concrete in American textbooks, such as "zebrafish", "coffee cup", "colored cellophane" and etc. Marking the name of materials specifically can play a favorable role in guiding inquiry learning activities, and contribute students to combining general concept with concrete representation, starting from cognition of facts to analyze the essential and general characteristics of things, and conducting inquiry activities smoothly.

\section{Comparison on Arrangements of Teachers' and Students' Inquiry Activities}

Teachers and students are the important elements of the teaching activities. The analysis and study on teacher-students interactions in the inquiry activities are beneficial to discussing the thinking essence of inquiry activities. From the statistical results of inquiry activities in which teachers and students participate in Sino-US high school biology textbooks, it can be found that there are two obvious differences (see table 2).

Table 2. The statisticstable of teacher-students interactions in the inquiry activities of Sino-US biology textbooks.

\begin{tabular}{lll}
\hline Textbooks & teachers' activities & students' activities \\
\hline Chinese textbooks & nothing & $\begin{array}{l}\text { Make hypotheses; design experimental scheme; discuss, revise and improve the activity } \\
\text { plan through group cooperation; complete inquiry activities; record the results }\end{array}$ \\
American textbooks & $\begin{array}{l}\text { Review the students' activities scheme, } \\
\text { make safety tips, and guide students to } \\
\text { clean and organize laboratory. }\end{array}$ & $\begin{array}{l}\text { Make hypotheses; design experimental scheme; discuss, revise and improve the activity } \\
\text { plan through group cooperation; complete inquiry activities; record the results; clean and } \\
\text { organize materials }\end{array}$ \\
\hline
\end{tabular}

\subsection{The Teachers' Guiding Tasks Are Clear in American Inquiry Activities}

Inquiry activities in American high school biology textbooks include not only students' activities, but also teachers' guiding tasks for the activities. For example, in a inquiry activity "the sensitivity of bacteria to different antibiotics", the descriptions related to teachers' activities include "Follow instructions of the teacher to deal with cotton swabs, culture mediums and culture dishes", "check your experimental materials given by the teacher", "get your teacher's allowance before the start of experiment", and "discuss the methods for dealing with waste bacteria culture and antibiotics after experiment with your teacher". It shows that in the arrangement of textbooks to inquiry activities, teachers' guiding role is clear in the activities.

Inquiry activities in Chinese textbooks emphasize students' subjectivity, so all the descriptions are about student activities and the descriptions about teachers how to guide activities are rarely mentioned in the design of teacher-students interactions. If the teachers' professional ability is not up to a certain degree, they will be confused when guide students in inquiry learning activities, and the quality of students' inquiry learning will be lack of guarantee. Constructivism advocates "scaffolding instruction". Scaffolding instruction is to provide a set of appropriate conceptual framework to help students understand knowledge and construct knowledge, in which teacher's role is to make the conceptual framework as perfect as possible. Based on the elements of scaffolding instruction, teachers' control on the classroom teaching activities needs to grasp at least two points at the time of teaching, the first one is to introduce students to a certain problem situation, and then provide them the necessary tool to solve the problem; second one is to build the scaffold and guide the exploration [19]. From this point of view, teachers' role is indispensable in the process that students construct knowledge. Aiming at this problem, it is necessary for textbooks to highlight the guiding role of teachers and give proper arrangements for teachers' activities in the inquiry 
activities, making teachers clear their tasks in the inquiry activities. At the same time, teachers should also recognize this problem, exert subjective initiatives, supplement the lack of teachers' activities in the textbooks by themselves, and then give full play to the guiding role in inquiry activities.

\subsection{The Arrangements of Students' Activities Are Relatively Specific in American Textbooks}

For students' activities in inquiry activities, Chinese textbooks descript in a relatively broad way, generally describing the students' main operating process of inquiry activities, without the descriptions of activities' details. For instance, in the activity "exploring the way of cellular respiration in yeast", Chinese textbooks only present the steps of activity, without detailed expression. However, at the inquiry activity also about yeast--"whether temperature will affect respiration in yeast", American textbooks, for the descriptions of students' activities, have not only process arrangements, but also details arrangements and tips to students activities, like "please wear goggles", "it is forbidden to touch the top of heater", "wash your hands at the end of the experiment", "properly handle BTB wastewater at the end of the experiment" and "if you need more help, please refer to the technical manual". It is very detailed in the experimental safety, experimental specifications and other aspects. Arranging students' activities carefully can enhance the operability of inquiry activities and the guidance of activities to students, which makes the inquiry activities implemented more smoothly.

\section{Conclusions}

Through the above research results and analysis, conclusions can be obtained is that the American high school biology teaching attaches great importance to experiment, and the proportion of experimental inquiry in American textbooks is far more than its in Chinese textbooks, but the proportion of the investigative inquiry activities in Chinese textbooks is higher than its in American textbooks. The result shows that investigative inquiry activities still are key points in Chinese high school, and the experimental inquiry activities compared with American textbooks have not been prominent in Chinese high school. Besides, inquiry activities in American textbooks pay more attention to selecting some common daily necessities, but there is nearly no daily necessity showing up in Chinese textbooks. The arrangement of textbooks ensures the standardability of experimental operation, but from the level of implementation, the experimental cost is relatively high. At last, the teachers' guiding tasks are clear in American inquiry activities, however, inquiry activities in Chinese textbooks emphasize the subjectivity of students and rarely mention how teachers to guide activities, which challenges to the professional level of teachers.

\section{Some Suggestions on Improving the Quality of Inquiry Learning}

Rogers' humanistic theory thinks that most meaningful learning is to learn by doing, so carrying out inquiry learning activities in classroom to promote students thinking by operating with hands is an important way to improve students' comprehensive quality. From the comparison of the inquiry activities in two countries' textbooks, it can be seen that the design and arrangement of the inquiry activities in Chinese textbooks have their own characteristics and some shortcomings. As a proverb goes, "There are other hills whose stones may serve to polish the jade". Learning from the advantages of international education and starting from the reality of school, Chinese high schools can optimize scientific inquiry learning activities through teachers' teaching research activities from following aspects.

\subsection{Focus on the Expansion of Knowledge and Enrich the Content of Textbooks}

The content of inquiry activities in Chinese high school biology textbooks (PEP edition) pays attention to the correlation with textbooks' main knowledge, and mainly delineates the content of inquiry learning within key and difficult knowledge, which is conducive to the formation of the scientific concept, but is bad to open up the horizons of learning. In order to improve students' interests in learning and make the content of inquiry activities rich, teachers should pay attention to the extension of knowledge while solving the key and difficult points in teaching. On the basis of a lot of reading and understanding of the relevant knowledge, teachers can collect and study learning content related to the inquiry activities, and then make appropriate supplement in the class, really using textbooks to teach rather than teaching textbooks, which will make the content of inquiry activities in the classroom richer and more meaningful, stimulate the students' learning potential and promote the development of students' learning ability.

\subsection{Enhance the Awareness of Innovation and Develop the of Activities}

The equipments of activities in Chinese textbooks are often limited to subject professional materials, so there is much room for the infiltration of life elements, which provides an opportunity for teachers to explore the teaching innovation. Teachers should be good at discovering daily necessities and utilizing them in inquiry activities, and also should exert students' imagination to transform and utilize some common items, making the equipments of inquiry activities diverse. According to the environmental characteristics of different regions and schools, teachers should select the appropriate equipment to assist teaching and enrich the content of activities. This process is not only the procedure of showing teachers' wisdom and innovative ability in teaching, but also the procedure of exerting students' imagination and improving students' innovative ability in learning.

\subsection{Pay Attention to Detail Design and Improve the Quality of Inquiry Activities}

A good teacher is like a good architect. He shows 
originality to the design of inquiry activities in the details, improving the quality of inquiry learning activities. Teachers can learn from the advantages of the arrangement of details in foreign textbooks, and optimize the details of inquiry activities. For example, when students carry on investigative inquiry in the community, teachers must establish rules and norms to regulate the behavior of students, like teaching students the etiquette of visiting, telling them that you have to ask for people's permission before you refer to some records or take a photograph [19] and etc. That will make inquiry activities implemented smoothly, and at the same time make the students' practical ability, thinking imagination and cognitive level of scientific concept improved.

Scientific inquiry is a new way of learning advocated by China since the new century and the quality of inquiry teaching activities plays an important role in the cultivation of high-quality talents. [20] The types of inquiry activities, the arrangements of teachers' and students' activities and the equipments of inquiry activities are closely related to the implementation quality of inquiry activities. The comparison and analysis above are the reflection and exploration to the quality of inquiry learning activities, and also are further understanding to the theory of inquiry learning based on teaching practice. Because the comparative study on Chinese and foreign textbooks is a dynamic development process, I believe this is just the beginning.

\section{References}

[1] Qin Chen, Lijuan Pang. Scientific inquiry: essence, characteristics and process. Education Science, Vol. 21, No. 1, 2005, pp. 1-5.

[2] Ministry of Education of the People's Republic of China. The General High School Biology Curriculum Standard (Experimental edition). Beijing: People's Education Press, 2003.

[3] Yangpu Huang. Comparative study on Sino-US high schools biology textbooks. Tsinan, Shandong Normal University, 2015.

[4] Wenjun Pan. Comparative study of Sino-US high school biology curriculum standards and textbooks. Chongqing: Chongqing Normal University, 2013.

[5] Qing Dai, Fengping Jiang. Comparative study on ecology in Sino-US high school biology textbooks. Modern Primary and secondary education, Vol. 32, No. 6, 2016, pp. 119-123.
[6] Lingyu Meng. Comparative study on ecology in Sino-US high school biology textbooks. Harbin: Harbin Normal University, 2016.

[7] Lingshi Zhang. Comparative study on the content of career education in Sino-US high school biology textbooks. Wuhan: Central China Normal University, 2015.

[8] Yufan Liao. Comparative study on the scientific content system of genetic in Sino-US high school biology textbooks. Changchun: Northeast Normal University, 2014.

[9] Min Gao. Comparative study on the history of life science in Sino-US high school biology textbooks. Xi'an: Shaanxi Normal University, 2013.

[10] Shide Zheng. Comparative study of critical thinking in Sino-US high school biology textbooks. Xi'an: Shaanxi Normal University, 2014.

[11] Shan Zhao. Comparative study on the difficulty of exercises between Chinese and American high school biology textbooks. Shanghai: East China Normal University, 2016.

[12] Sha Zhang. Comparative study on exercises system between Chinese and American high school biology textbooks. Guilin: Guangxi Normal University, 2015.

[13] Na Yao. Comparative study on exercises between Chinese and American high school biology textbooks. Xi'an: Shaanxi Normal University, 2014.

[14] Shuangxu Han. Comparative study of synchronous network instructional resources between Chinese and American high school biology textbooks. Xi'an: Shaanxi Normal University, 2015.

[15] Hong Zhu. Comparative study of ecological experiments in Chinese and American high school biology textbooks. Nanjing: Nanjing Normal University, 2014.

[16] Wenshuo Zhang. Comparative study on inquiry activities in BSCS (Blue Book) and Chinese high school biology textbooks. Changchun: Northeast Normal University, 2014.

[17] Xuefu Xu. Scientific inquiry and inquiry teaching. Curriculum, Teaching Material and Method, No. 12, 2002, pp. 18-20.

[18] Shidong Zhou, Changlong Zheng, Lihai Fu. Types, Functions and Activity Modes of Scientific Inquiry Activities. Chinese Journal of Chemical Education, No. 4, 2005, pp. 10-11.

[19] Richard I. Arends. Learning to Teach. The McGraw- Hill Companies, INC, 2011.

[20] Xiangdong Ying. Philosophical Thought on Scientific Inquiry Teaching. Curriculum, Teaching Material and Method, Vol. 26, No. 5, 2006, pp. 65-67. 